\title{
Correction to: Can expensive research equipment boost research and development performances?
}

\author{
Kyoungmi Lee ${ }^{1,2} \cdot$ Sunglok Choi $^{3} \cdot$ Jae-Suk Yang ${ }^{1}$ ii \\ Published online: 19 November 2021 \\ ๑) Akadémiai Kiadó, Budapest, Hungary 2021
}

\section{Correction to: Scientometrics (2021) 126:7715-7742 https://doi.org/10.1007/s11192-021-04088-6}

In the original publication of the article, Table 5 was published with error. This has been corrected with this correction.

The original article can be found online at https://doi.org/10.1007/s11192-021-04088-6.

Jae-Suk Yang

yang@ kaist.ac.kr

1 Graduate School of Future Strategy, Korea Advanced Institute of Science and Technology, Daejeon 34141, Republic of Korea

2 National Research Facilities and Equipment Center, Korea Basic Science Institute, Daejeon 34133, Republic of Korea

3 Department of Computer Science and Engineering, Seoul National University of Science and Technology, Seoul 01811, Republic of Korea 


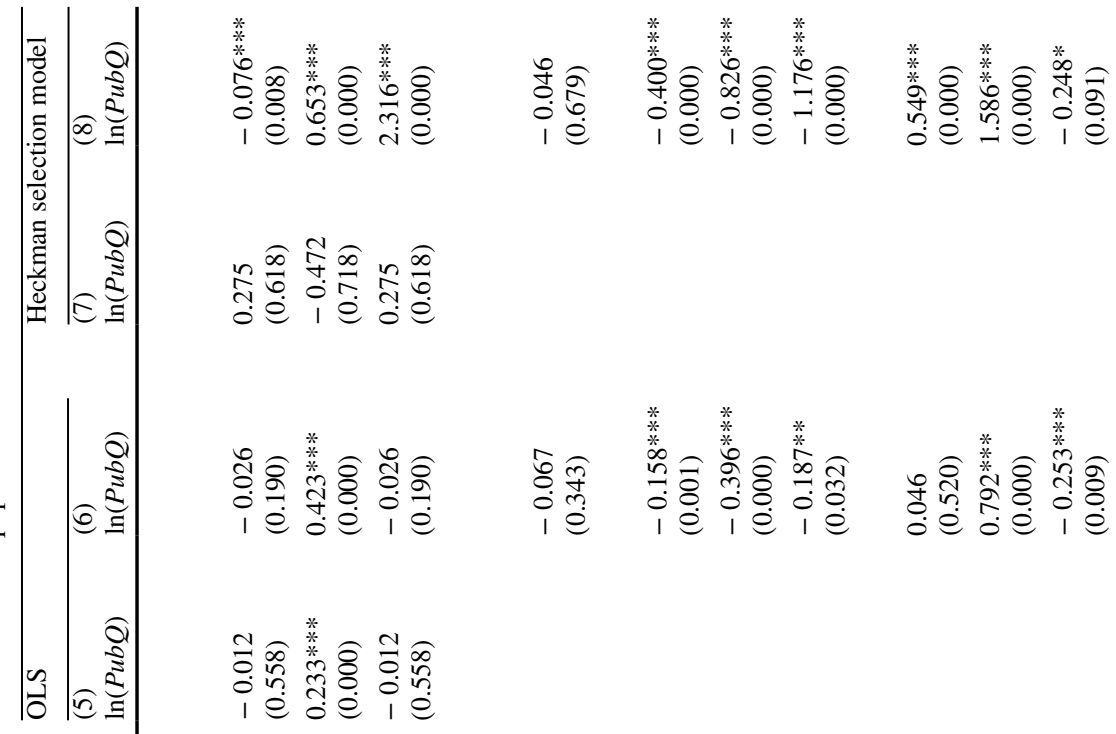

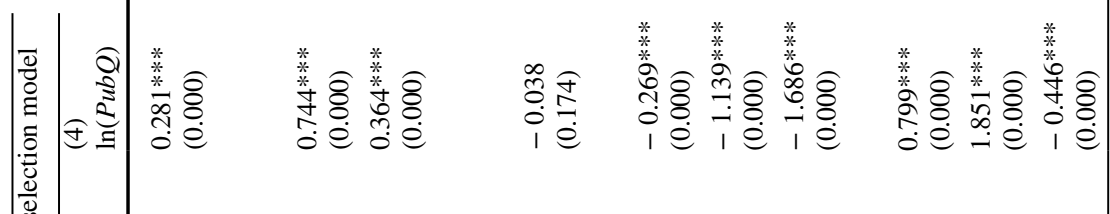

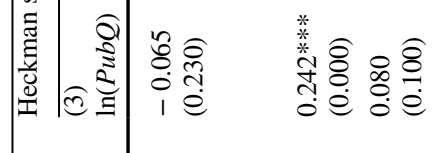

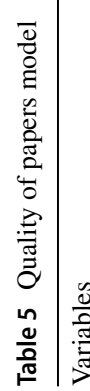

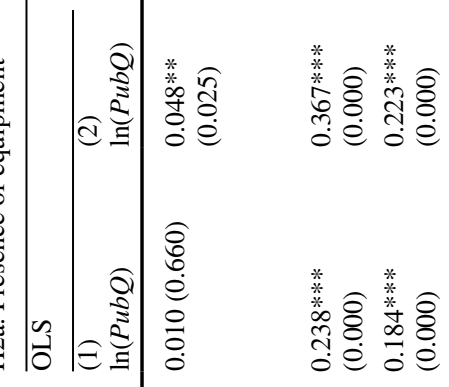

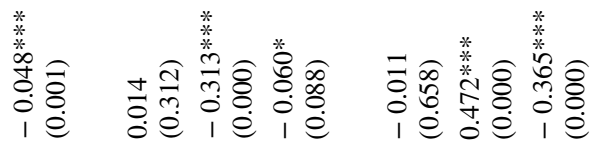

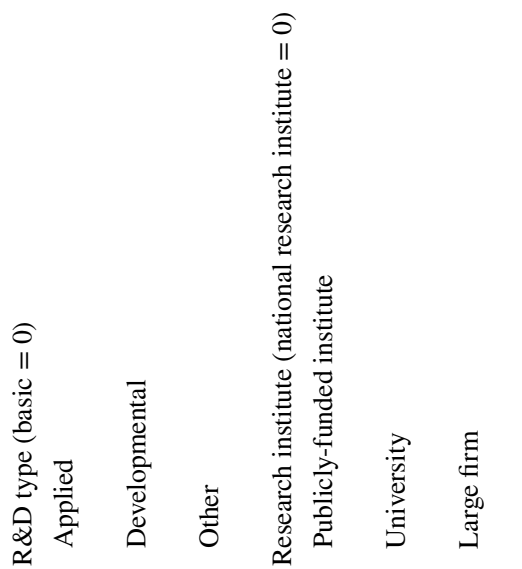




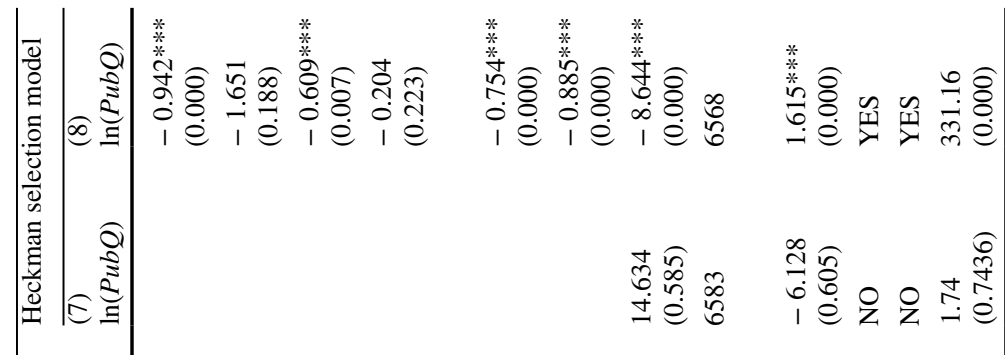

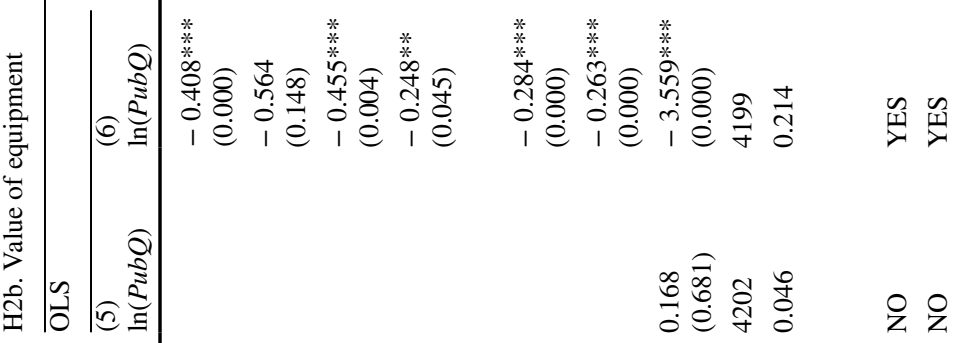

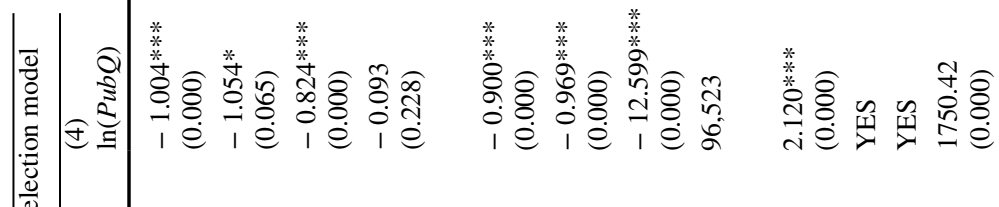

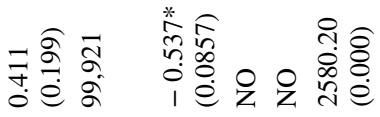

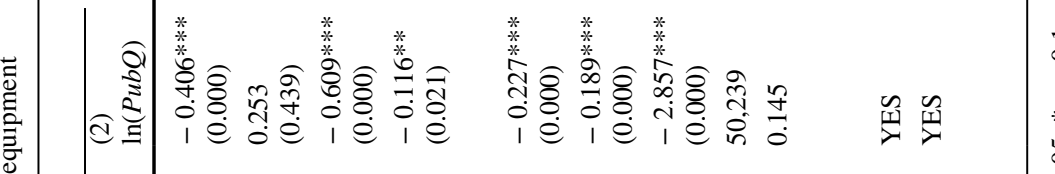

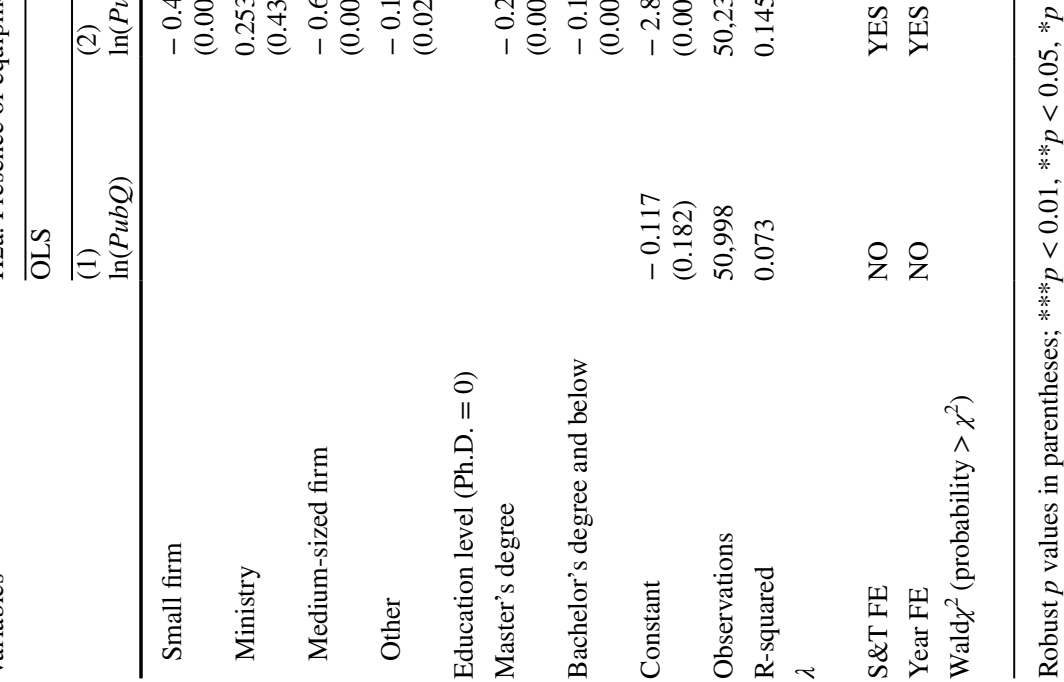

